\title{
Variações temporais e espaciais da precipitação em áreas urbanas: estudo de caso na região oeste do município de Belo Horizonte
}

Wellington Lopes Assis*

\begin{abstract}
Resumo
O objetivo dessa pesquisa foi analisar as variabilidades temporais e espaciais da precipitação durante dois períodos de trinta dias na época chuvosa nos bairros Buritis e Estoril, localizados na região Oeste do município de Belo Horizonte. Avaliou-se a influência da topografia, da altitude e da morfologia urbana no aumento das instabilidades atmosféricas e nos totais pluviométricos diários. Para a análise dos dados e escolha dos pontos amostrais, foram elaborados um modelo digital de elevação e um mapa de uso do solo. A leitura da precipitação foi padronizada para $12 \mathrm{~h}$ GMT, correspondendo ao total acumulado de 24h. A identificação e interpretação dos tipos de tempo foram possibilitadas pelo uso de gráficos de análise rítmica, cartas sinóticas e imagens de satélites. Os experimentos indicaram uma alta correlação entre rugosidade superficial e quantidade de chuva precipitada, comprovando os efeitos da topografia no aumento das instabilidades atmosféricas.

Palavras-chaves: Precipitação; Clima urbano; Pluviômetros de campo.
\end{abstract}

* Professor do Centro Universitário de Belo Horizonte (assisw@gmail.com e wlopes@acad.unibh.br).

Geosul, Florianópolis, v. 24, n. 48, p 177-196, jul./dez. 2009 
ASSIS, W.L. Variações temporais e espaciais da precipitação em áreas ...

Temporal and spacial variabilities of precipitation in urban areas places: case study in the west region of Belo Horizonte city

\begin{abstract}
The objective of this research was to analyse the temporal and spacial variabilities of precipitation during two thirty-day periods of the rainy season in the Buritis and Estoril districts, both of them located in the West region of Belo Horizonte. The influence of topography, altitude and morphology in the increase of urban atmospheric instability and the daily rainfall totals were evaluated. In order to analyse the data and selection of the sample sites, a digital model of elevation and a map of the use of the ground were prepared. The precipitation reading was standardized for $12 \mathrm{~h} \mathrm{GMT}$, corresponding to the accumulated total of $24 \mathrm{~h}$. The identification and interpretation of the types of weather were possible by using graphics of rhythmic analysis, sinotical map and satellite images. The experiment indicated high correlation between irregular topography and the amount of precipitated rain, proving the effect of the morphology on the increase of the atmospheric instability.
\end{abstract}

Key words: Precipitation; Urban climate; Field precipitation gauges.

\title{
Introdução
}

No meio científico há um consenso de que sobre as cidades são criados padrões de circulação atmosférica específicos, responsáveis por alterações nas características das precipitações, tanto nos totais acumulados como na distribuição espacial. Essas mudanças variam muito de acordo com o porte da cidade, das funções urbanas desempenhadas e dos ritmos atmosféricos associados a estas transformações.

Embora o teor de umidade relativa do ar seja menor dentro do tecido urbano, especialmente em áreas desprovidas de vegetação ou laminas d'água, a precipitação que aí ocorre é 
ASSIS, W.L. Variações temporais e espaciais da precipitação em áreas ...

geralmente maior que a verificada no campo (AZEVEDO, 2002; LANDSBERG, 1981; LOWRY, 1998; THIELEN, J. e GADIAN, 1997). Porém, nem sempre é possível estabelecer uma relação direta entre urbanização e aumento nas chuvas, pois fatores como topografia e sistemas sinóticos influenciam esse parâmetro a ponto de minimizar, ou mesmo anular, os efeitos antrópicos.

Os bairros Buritis e Estoril, localizados na região Oeste do município de Belo Horizonte, possuem feições topográficas e morfológicas que favorecem a intensificação das instabilidades atmosféricas. O relevo da área de estudo é bastante irregular, apresentando variações altimétricas de $860 \mathrm{~m}$ a $1240 \mathrm{~m} \mathrm{em}$ distâncias lineares inferiores a $800 \mathrm{~m}$. Somando-se a essas características, o tecido urbano aumenta a rugosidade superficial pela presença de grandes edifícios. Nos últimos anos a região vem passando por profundas modificações em seu quadro natural; houve acréscimo significativo no número de habitações acima de oito pavimentos e intensa impermeabilização do solo.

O objetivo dessa pesquisa foi analisar as variabilidades temporais e espaciais da precipitação durante dois períodos de trinta dias na época chuvosa nos bairros Buritis e Estoril, conhecendo as formas de interações entre topografia-morfologia e o uso do solo nos totais pluviométricos diários.

\section{Materiais e métodos}

Para atingir o objetivo proposto foram confeccionados cinco pluviômetros de campo utilizando materiais obtidos em canteiros de obras e entulhos. Dentre esses, destacam-se tubos e tampões de PVC de $100 \mathrm{~mm}$ e caibros para fixação dos equipamentos nos pontos amostrais (FIG. 1 e 2). Somente as torneiras e os funis, ambos de plástico, foram comprados. Esses últimos foram colocados na borda superior do pluviômetro para evitar a perda por evaporação da água precipitada.

Seguindo o padrão de construção dos pluviômetros utilizados em estações agrometeorológicas, optou-se pela forma cilíndrica para os equipamentos empregados em campo. De acordo 
ASSIS, W.L. Variações temporais e espaciais da precipitação em áreas ...

com Varejão-Silva (2000), essa configuração oferece condições idênticas de exposição ao vento, qualquer que seja a direção deste nas vizinhanças imediatas ao pluviômetro.

Para a medida da chuva acumulada utilizou-se uma proveta de plástico de $250 \mathrm{ml}$ acoplada a uma régua graduada. Para evitar possíveis erros nas leituras, as provetas foram devidamente niveladas e a quantidade de precipitação era então indicada, usando-se como referência o plano tangente ao menisco da coluna líquida.

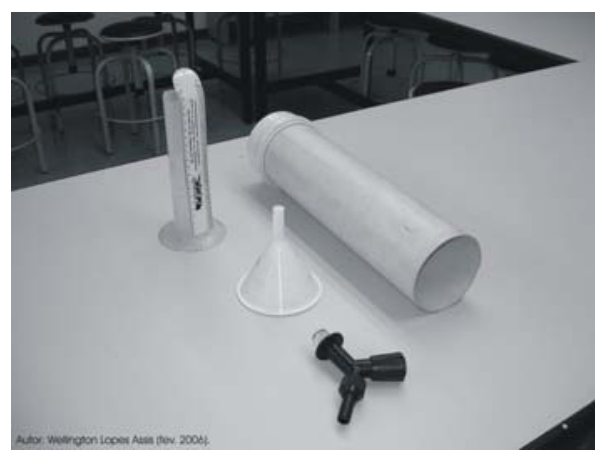

Figura 1: Materiais utilizados na confecção dos pluviômetros de campo.

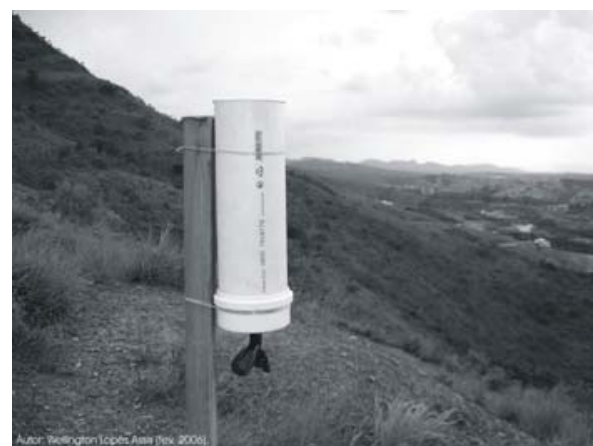

Figura 2: Pluviômetro de campo instalado no ponto 3, Serra do Cercadinho. 
ASSIS, W.L. Variações temporais e espaciais da precipitação em áreas ...

Segundo Barry e Chorley (2003) e Vianello e Alves (1991) o volume da chuva captado por um pluviômetro em determinado local depende de fatores como velocidade dos ventos, taxa de evaporação, obstáculos e a altura do pluviômetro acima do solo. Em relação a esse último fator, fixou-se os pluviômetros de campo a uma altura padrão de 1,50m da superfície (FIG. 3 e 4).

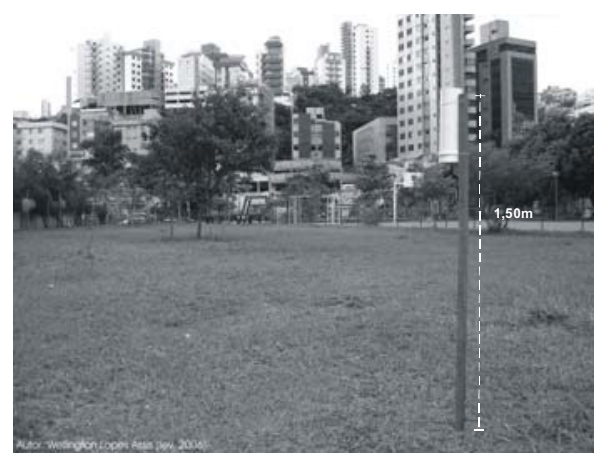

Figura 3: Pluviômetro de campo instalado no ponto 4, Parque Municipal Aggeo Pio Sobrinho, à jusante do córrego Ponte Queimada.

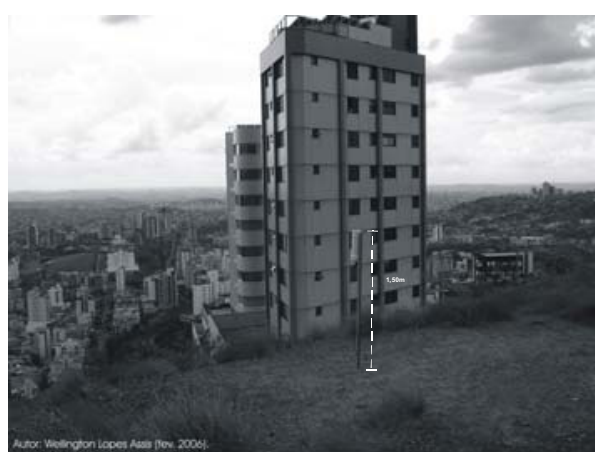

Figura 4: Pluviômetro de campo instalado no ponto 3, Serra do Cercadinho. Apesar da litologia e declividade desfavorável à ocupação, houve intensa urbanização e verticalização nos últimos anos. 
ASSIS, W.L. Variações temporais e espaciais da precipitação em áreas ...

Para a escolha e distribuição dos pontos amostrais confeccionou-se um modelo digital de elevação (FIG. 5) e um mapa de uso do solo (FIG. 6). Os equipamentos foram instalados em cinco locais dentro dos bairros Buritis e Estoril, tendo a preocupação de se evitar qualquer obstáculo capaz de interferir no volume de chuva coletado, principalmente edificações e árvores. $\mathrm{O}$ sexto ponto foi a estação meteorológica do Centro Universitário de Belo Horizonte (UNI-BH).

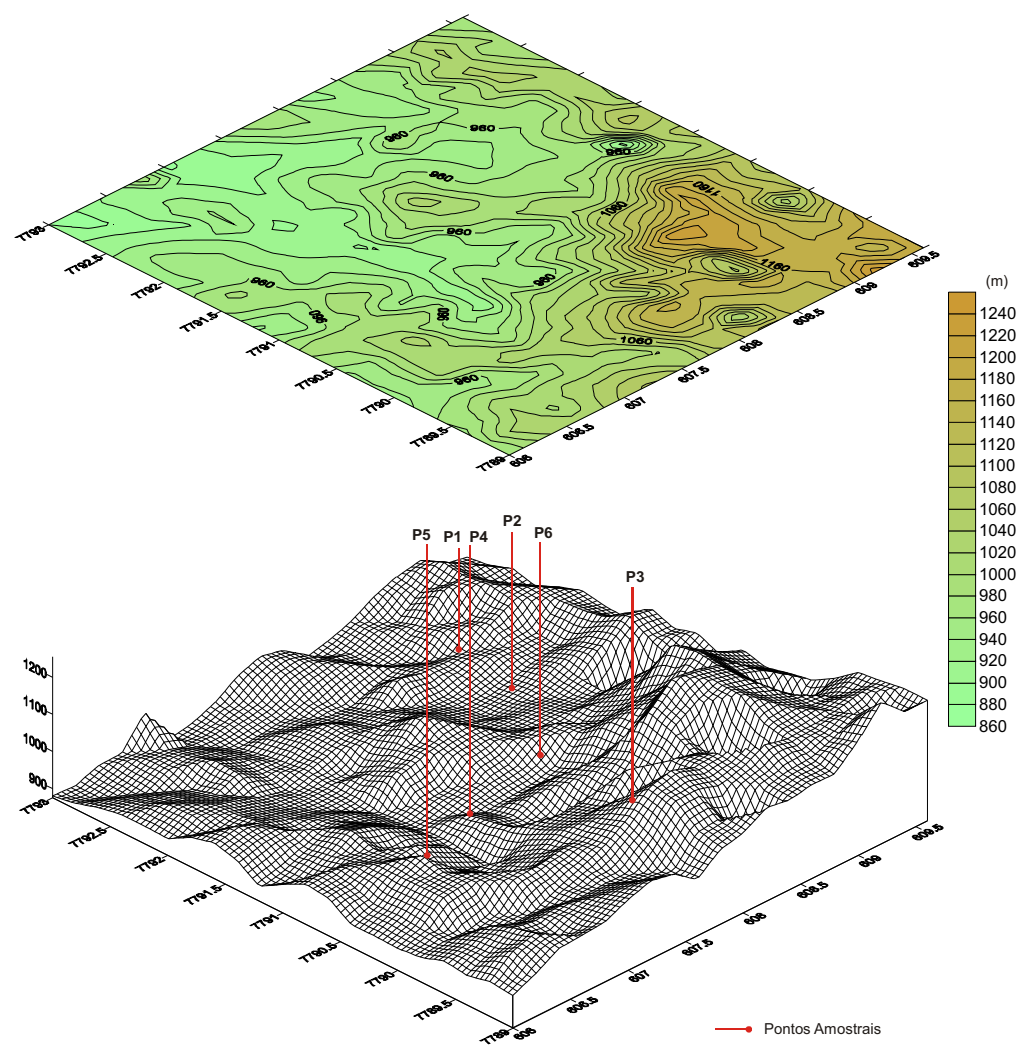

Figura 5: Modelo digital de elevação dos bairros Buritis e Estoril com a localização dos pontos amostrais. 
ASSIS, W.L. Variações temporais e espaciais da precipitação em áreas ...

A leitura da precipitação diária foi padronizada para $12 \mathrm{~h}$ GMT, correspondendo ao total acumulado de $24 \mathrm{~h}$ a contar do dia anterior. A altura da chuva foi registrada entre os dias 15 de fevereiro e 16 de março de 2006 e entre os dias 7 de novembro e 14 de dezembro de 2007.

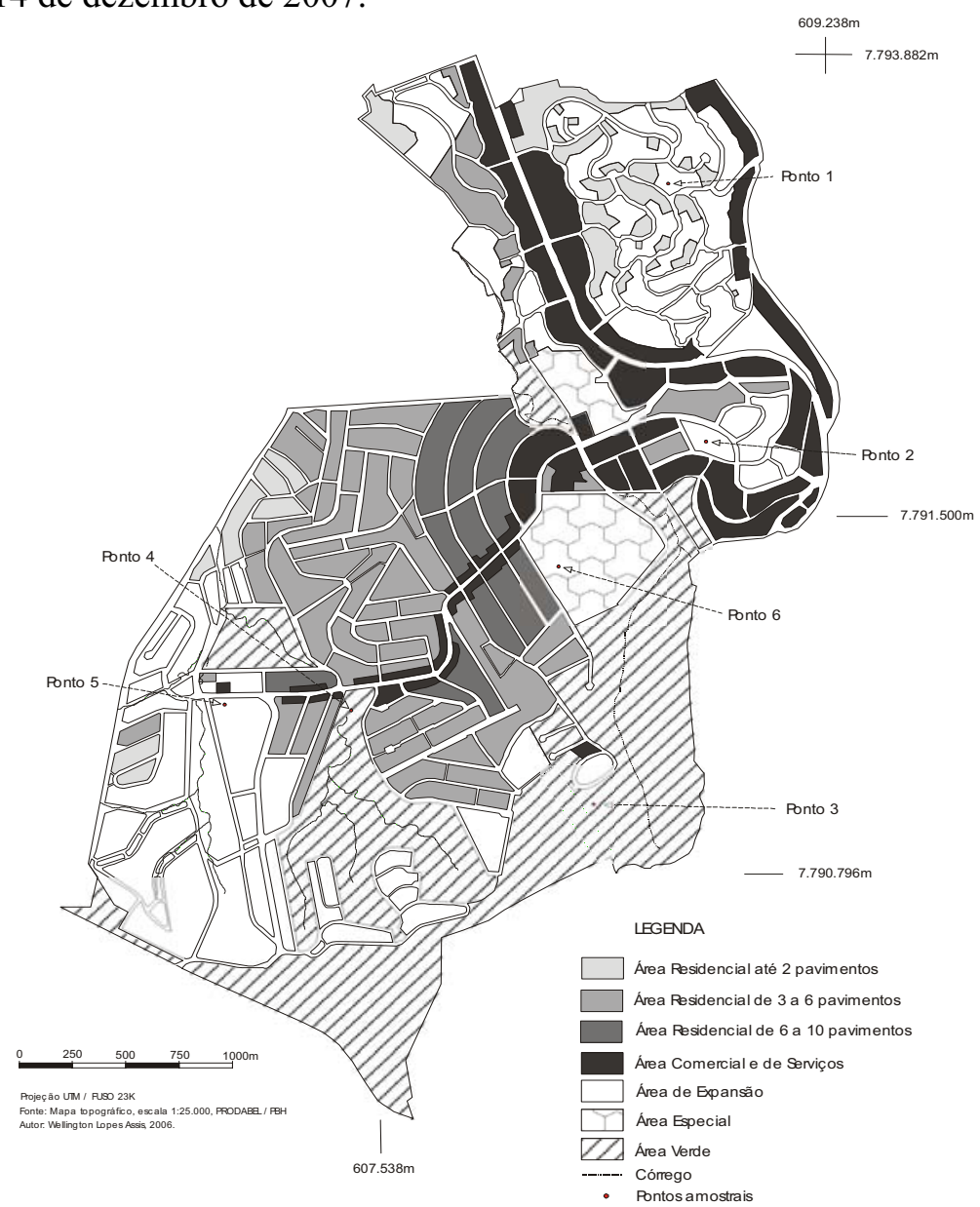

Figura 6: Mapa de uso do solo dos bairros Buritis e Estoril com a localização dos pontos amostrais. 
ASSIS, W.L. Variações temporais e espaciais da precipitação em áreas ...

A análise dos tipos de tempo observados no período da coleta foi realizada tendo como instrumental teórico-metodológico os gráficos de análise rítmica (MONTEIRO, 1971). Como subsídios à interpretação da dinâmica atmosférica foram utilizadas cartas sinóticas de $12 \mathrm{~h}, 18 \mathrm{~h}$ e $24 \mathrm{~h}$ GMT, obtidas no $\mathrm{DHN}^{1}$ (Diretoria de Hidrografia e Navegação), e imagens meteorológicas do satélite GOES- $8^{2}$ nos referidos horários sinóticos.

Antes da coleta dos dados, todos os pluviômetros de campo foram aferidos com o pluviômetro da estação meteorológica do UNI-BH. Como todos os registros em campo foram obtidos em centímetro $(\mathrm{cm})$, foi necessário padronizar e converter a altura da chuva captada nos equipamentos para milímetro $(\mathrm{mm})$.

As características volumétricas dos pluviômetros de campo foram determinadas através dos seguintes cálculos:

$$
\begin{array}{r}
\text { VOLcap }=\text { Acap } . h \quad \text { VOLcap } \\
\text { Acap }
\end{array}
$$

onde,

$\mathrm{h}=$ altura diária da chuva em milímetro $(\mathrm{mm})$

VOLcap $=$ volume de água captada no pluviômetro $\mathrm{em}^{\mathrm{cm}}$

Acap = área da superfície de captação em $\mathrm{cm}^{2}$

Utilizando a proveta: VOLcap $=$ VOL prov

Acap . $\mathrm{h}=$ aprov. Hprov.

Se $\mathrm{k}=10$ (Acap é dez vezes aprov), e $1 \mathrm{~cm}$ na proveta equivale a $1 \mathrm{~mm}$ de chuva.

Pelo processo de interpolação linear foi possível visualizar a variação espacial da precipitação e confeccionar cartogramas com a distribuição das isoietas.

Posteriormente, todas as informações obtidas em campo foram comparadas com os dados oficiais da estação meteorológica pertencente ao $5^{\circ}$ Distrito de Meteorologia ( $5^{\circ} \mathrm{DISME} / \mathrm{INMET}$ ),

${ }^{1}$ Disponível em http://www.dhn.mar.mil.br

${ }^{2}$ Disponível em http://www.cptec.inpe.br 
ASSIS, W.L. Variações temporais e espaciais da precipitação em áreas ...

buscando verificar as amplitudes e variações dos totais pluviométricos diários em cada ponto amostral.

\section{Análise e discussão dos resultados}

\section{Primeiro trabalho de campo (15/02/06 a 16/03/06)}

Neste primeiro experimento, as condições de tempo e os sistemas atmosféricos observados apresentaram características típicas de verão, instabilidades localizadas e fortes chuvas no final da tarde e início da noite. Os totais diários mais significativos ocorreram quando da atuação da Zona de Convergência do Atlântico Sul (ZCAS) e de Linhas de Instabilidade (LI) associadas à atuação da Frente Polar Atlântica (FPA) na região sudeste.

O mês de fevereiro registrou a participação de somente dois episódios de ZCAS na região metropolitana de Belo Horizonte (RMBH): o primeiro iniciou no dia 27 de janeiro de 2006 e durou até o dia 02 fevereiro e o segundo ocorreu entre os dias 09 e 13 do respectivo mês e ano. Nos demais dias as precipitações foram basicamente de caráter convectivo, o que refletiu nos totais pluviométricos diários dos pontos amostrais.

No mês de março as chuvas excederam a climatologia em grande parte da região sudeste, principalmente devido à atuação da ZCAS na primeira quinzena deste mês. Nesses episódios, foram reconhecidos os sistemas atmosféricos associados ao modelo conceitual de ZCAS: presença da Alta da Bolívia, do Vórtice Ciclônico do Nordeste em 200hPa e do Cavado em 500hPa a oeste da área de velocidade vertical significativa (CLIMANÁLISE, 2006). Em alguns pontos da RMBH foram registradas fortes precipitações, que ocasionaram deslizamentos nos bairros periféricos, localizados nas encostas da Serra do Curral, e inundações em alguns córregos afluentes do ribeirão Arrudas.

A análise dos resultados mostrou que a precipitação variou temporal e espacialmente entre os pontos localizados na área de estudo e entre estes e o posto oficial do $5^{\circ}$ Distrito de Meteorologia. Alguns fatores estáticos contribuíram de forma 
ASSIS, W.L. Variações temporais e espaciais da precipitação em áreas ...

significativa, especialmente a topografia e morfologia do tecido urbano. Todos os pluviômetros de campo instalados nos bairros Buritis e Estoril obtiveram precipitações acumuladas (FIG. 7), e médias diárias, superiores ao observado no posto do $5^{\circ}$ DISME/INMET.

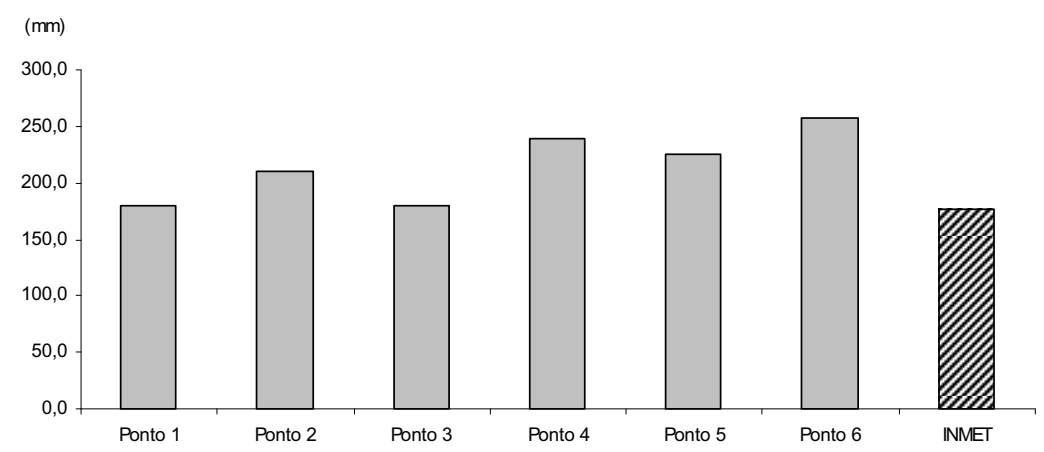

Figura 7: Precipitação acumulada nos pontos amostrais e no $5^{\circ}$ Distrito de Meteorologia, período compreendido entre os dias 15/02/2006 e 16/03/2006.

Nesse primeiro trabalho de campo os pontos 6 e 4 registraram os maiores volumes de chuva acumulada; $257,4 \mathrm{~mm}$ e $234,8 \mathrm{~mm}$ respectivamente, e as mais elevadas médias diárias pontuais. Nesses locais foram coletadas as precipitações mais intensas ocorridas em um único dia; cerca de 42mm em 05/03/2006 (FIG. 8).

Os altos índices registrados nos pontos 6 e 4 podem ser explicados pelo fato da topografia ser bastante acidentada localizam-se no sopé da Serra do Cercadinho - o que contribui para uma maior turbulência atmosférica e o aumento da instabilidade da parcela do ar.

Um outro fator que colabora para esse comportamento nesses pontos é o suprimento constante de umidade. O ponto 6 está próximo da área de preservação permanente e manancial da Companhia de Saneamento e Águas do Estado de Minas Gerais, 
ASSIS, W.L. Variações temporais e espaciais da precipitação em áreas ...

Reserva do Cercadinho, e o ponto 4 encontra-se no parque municipal Aggeo Pio Sobrinho. Essas localidades possuem uma extensa área verde protegida e os maiores remanescentes de vegetação natural encontrada na região Oeste do município, além de abrigarem as nascentes de dois afluentes do ribeirão Arrudas: o córrego Cercadinho e o córrego Ponte Queimada.

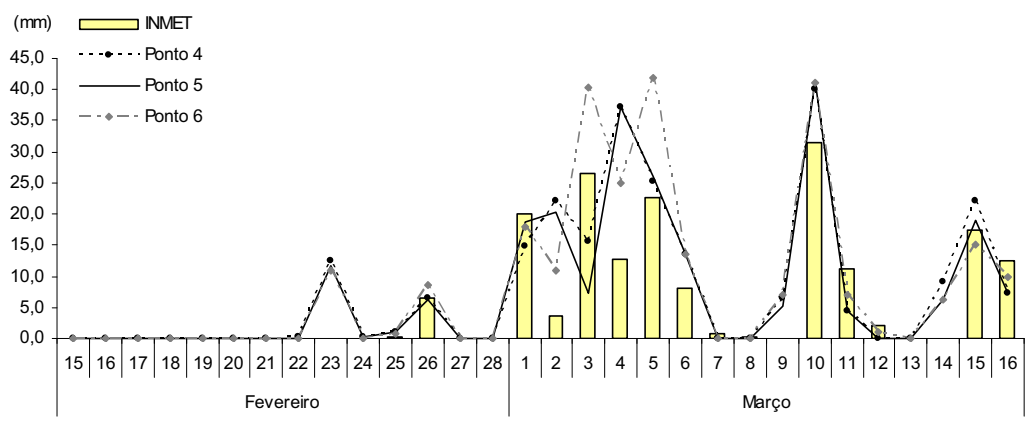

Figura 8: Precipitação acumulada diária nos pontos 4, 5, 6 e no $5^{\circ}$ Distrito de Meteorologia.

Os pontos 1 e 3 registraram os menores volumes de precipitação acumulada no período - $180,4 \mathrm{~mm}$ e $179,5 \mathrm{~mm}$ respectivamente - e as menores médias diárias pontuais (FIG. 9). O ponto 3 encontra-se em área densamente construída e verticalizada. Conjecturou-se que o raio de obstrução padrão de $50 \mathrm{~m}$, estabelecido pela Organização Mundial de Meteorologia, e adotado para determinar a fixação correta dos pluviômetros de campo, não foi suficiente para evitar o efeito de "sombreamento" causado pelas edificações.

Esse mesmo fator poderia justificar o menor volume de precipitação acumulado em alguns dias pela estação meteorológica do $5^{\circ}$ Distrito de Meteorologia, especialmente sob a atuação de instabilidades locais. No entorno do $5^{\circ}$ DISME/INMET existem grandes edifícios, a maioria deles acima de 10 pavimentos, e duas grandes avenidas que interligam o centro com a periferia da cidade. Somando-se a isso, a topografia da região é mais "suavizada" se 
ASSIS, W.L. Variações temporais e espaciais da precipitação em áreas ...

comparada com as transições abruptas de declividades observadas nos bairros Buritis e Estoril.

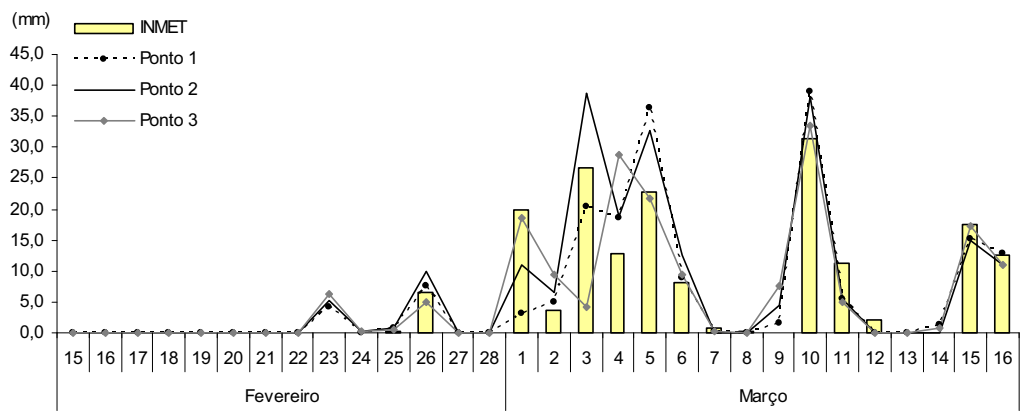

Figura 9: Precipitação acumulada diária nos pontos $1,2,3$ e no $5^{\circ}$ Distrito de Meteorologia.

$\mathrm{Na}$ figura 10 observamos a distribuição espacial da precipitação total acumulada neste primeiro trabalho de campo. Nota-se que o núcleo mais intenso está localizado na porção central e sudoeste da região.

Nos dias em que as precipitações registradas no município foram de baixa intensidade, ocasionadas essencialmente por instabilidades locais, os totais diários acumulados no $5^{\circ}$ DISME/INMET superaram em poucos milímetros alguns pontos da área de estudo - somente naqueles em que o acumulado diário não foi superior a $20 \mathrm{~mm}$. Já nos eventos de grande intensidade, característicos de forte instabilidade convectiva e atuação de sistemas frontais frios, os totais pluviométricos nos bairros Buritis e Estoril foram sempre superiores. 
ASSIS, W.L. Variações temporais e espaciais da precipitação em áreas ...

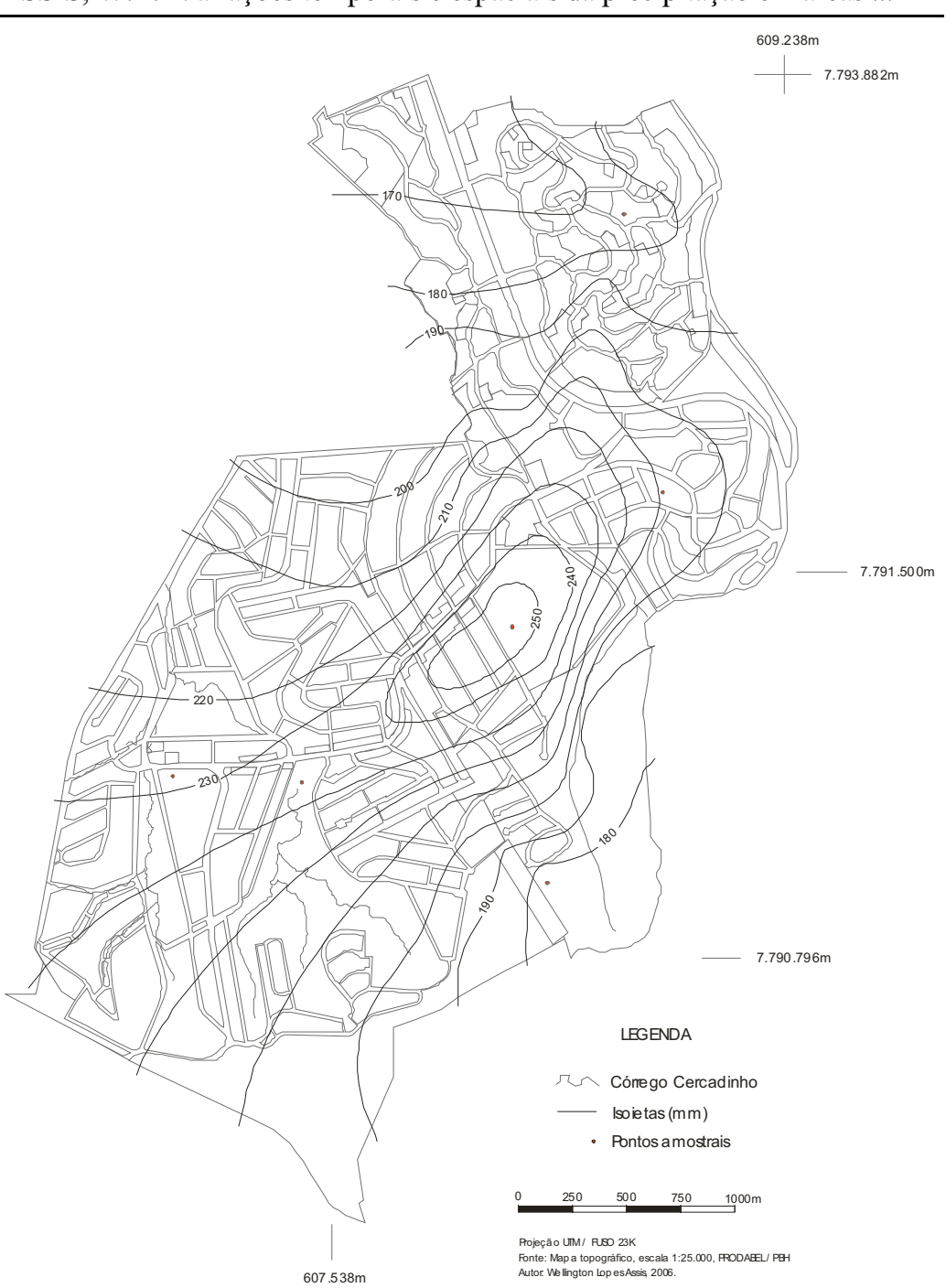

Figura 10: Mapa com a distribuição da precipitação acumulada no período compreendido entre os dias 15/02/2006 a 16/03/2006. 
ASSIS, W.L. Variações temporais e espaciais da precipitação em áreas ...

Em relação aos sistemas atmosféricos, observou-se que durante a participação da Massa Equatorial Continental $(\mathrm{mEc})$ e de Linhas de Instabilidades (LI) sobre o Região Metropolitana de Belo Horizonte, as precipitações eram basicamente de caráter convectivo, período compreendido entre 01/03/2006 e 06/03/2006 (FIG. 11). O intenso aquecimento superficial, associado à turbulência forçada pela topografia, resultou em eventos extremos e elevados totais acumulados diários nos pontos amostrais.

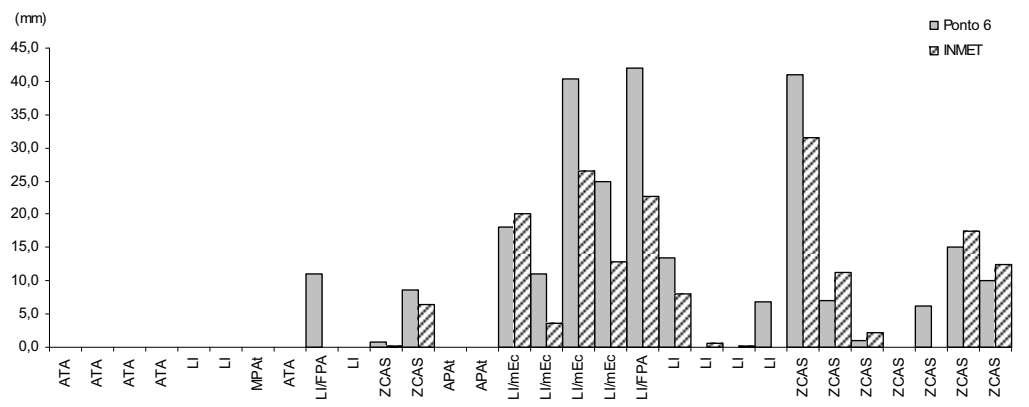

Figura 11: Precipitação acumulada diária no ponto 6 e no $5^{\circ}$ Distrito de Meteorologia e os sistemas atmosféricos atuantes, período compreendido entre os dias $15 / 02 / 2006$ e 16/03/2006.

\section{Segundo trabalho de campo (07/11/07 a 14/12/07)}

Nos primeiros três dias do segundo experimento não foi registrada nenhuma precipitação no município de Belo Horizonte. A atuação do Anticiclone Tropical do Atlântico Sul (ATA) proporcionou condições de estabilidade atmosférica em toda região metropolitana.

Do dia 13 até o dia 27 de novembro houve a participação de quatro frentes frias intercaladas por linhas de instabilidade. Este último sistema estava associado à passagem ou ao estacionamento de sistemas frontais no litoral da região sudeste.

Foi observado que quando da atuação da Frente Polar Atlântica (FPA) a precipitação diária acumulada apresentou 
ASSIS, W.L. Variações temporais e espaciais da precipitação em áreas ...

significativas variações entre os pluviômetros de campo e o pluviômetro oficial do $5^{\circ}$ DISME/INMET (FIG. 12).

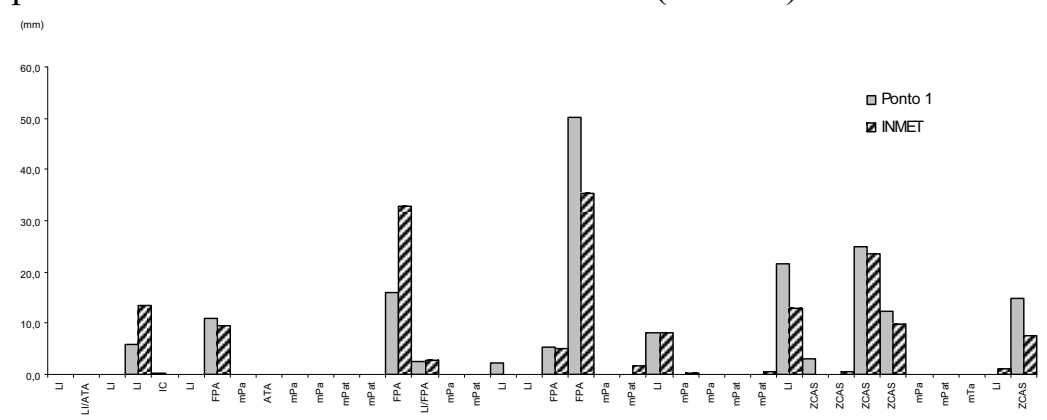

Figura 12: Precipitação acumulada diária no ponto 1 e no $5^{\circ}$ Distrito de Meteorologia e os sistemas atmosféricos atuantes, período compreendido entre os dias 07/11/07 a $14 / 12 / 07$.

A Zona de Convergência do Atlântico Sul participou das condições atmosféricas de Belo Horizonte em duas ocasiões (CLIMANÁLISE, 2007), seguindo o mesmo comportamento observado no primeiro trabalho de campo. Os maiores totais pluviométricos foram registrados durante a atuação da ZCAS.

Em determinados dias, o intenso aquecimento superficial, associado a grande disponibilidade de vapor d'água, estimulava a convecção e a instabilidade atmosférica. Esses mecanismos proporcionaram chuvas localizadas de curta duração ao final do dia em todos pontos amostrais. As precipitações dos dias 09, 11 e 24 de novembro são resultantes desse processo.

Neste segundo trabalho de campo, os pontos 1 e 2 registraram os maiores volumes de chuva acumulada, $177,8 \mathrm{~mm}$ e $170,9 \mathrm{~mm}$ respectivamente, e as mais elevadas médias diárias pontuais (FIG. 13).

O ponto 1 registrou a precipitação mais intensa ocorrida em um único dia, cerca de 50,1mm em 27/11/07 (FIG. 14). Os pontos 3 e 6 registraram os menores volumes de precipitação acumulada 
ASSIS, W.L. Variações temporais e espaciais da precipitação em áreas ...

no período, $167,1 \mathrm{~mm}$ e $164,7 \mathrm{~mm}$ respectivamente, e as menores médias diárias pontuais (FIG. 14 e 15).

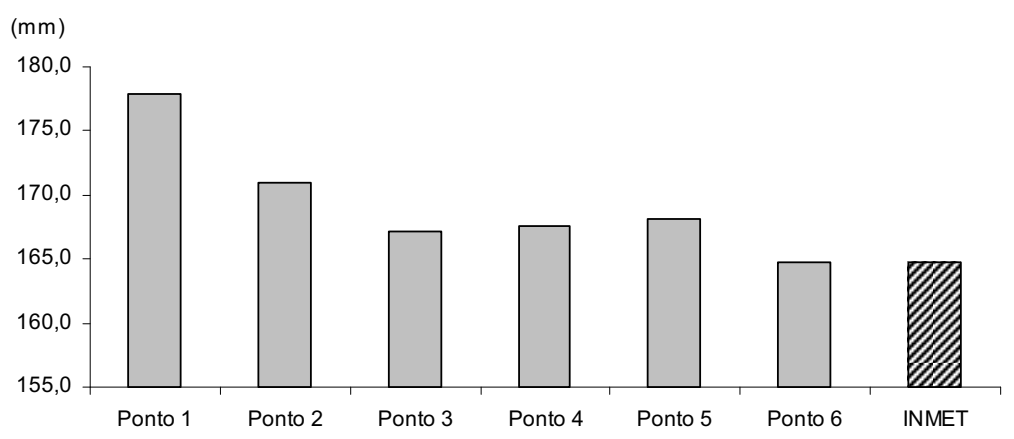

Figura 13: Precipitação acumulada nos pontos amostrais e no $5^{\circ}$ Distrito de Meteorologia, período compreendido entre os dias 07/11/2007 a 14/12/2007.

É importante ressaltar que nesse segundo experimento a amplitude na precipitação total acumulada entre os pontos amostrais, e entre esses o $5^{\circ} \mathrm{DISME} / \mathrm{INMET}$, foi bem menor do que a registrada no primeiro trabalho de campo - somente $10,7 \mathrm{~mm}$ contra $77,9 \mathrm{~mm}$ do primeiro.

Diferindo um pouco da distribuição espacial das isoietas observadas no primeiro experimento, nota-se na figura 16 que o núcleo mais intenso está localizado na porção norte e nordeste na área de estudo.

Nos dois trabalhos de campo, foi possível observar que durante a atuação da Frente Polar Atlântica e da Zona de Convergência do Atlântico Sul a variação nos totais diários entre os pontos amostrais eram menores. Isso comprova que fatores atmosféricos de larga escala tendem a "homogeneizar" a distribuição espacial das chuvas. 
ASSIS, W.L. Variações temporais e espaciais da precipitação em áreas ...

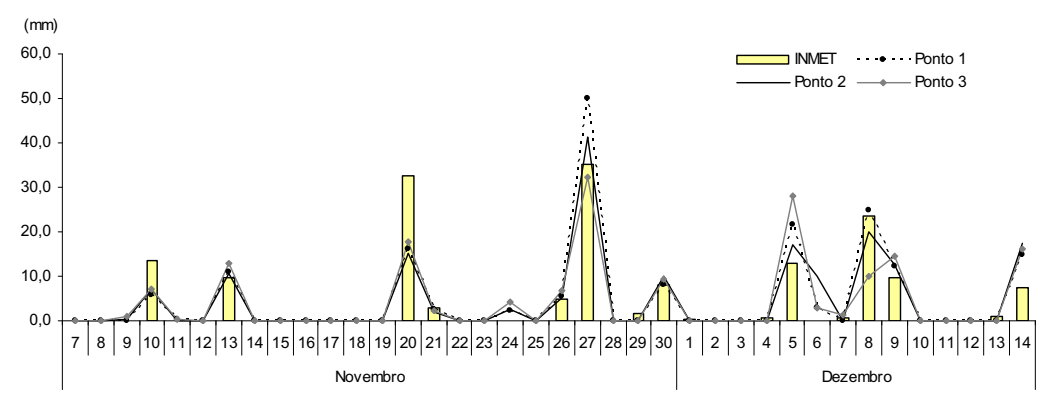

Figura 14: Precipitação acumulada diária nos pontos $1,2,3$ e no $5^{\circ}$ Distrito de Meteorologia.

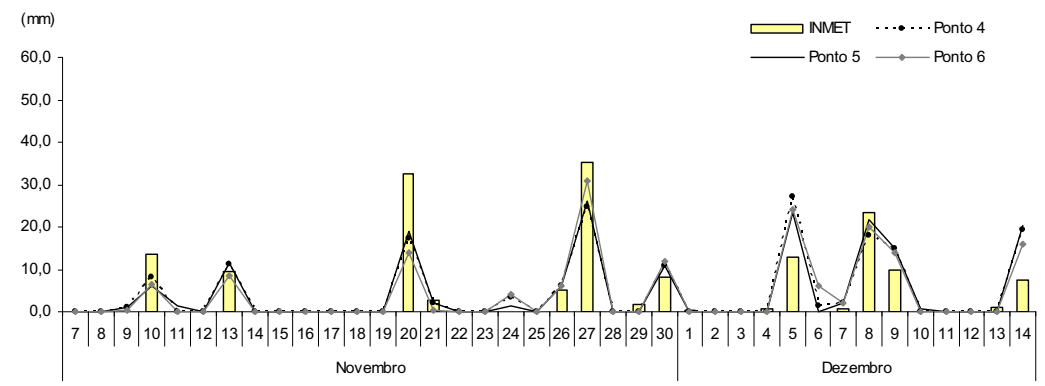

Figura 15: Precipitação acumulada diária nos pontos $4,5,6$ e no $5^{\circ}$ Distrito de Meteorologia.

Ao analisar isoladamente o parâmetro altimétrico, não foi possível observar uma relação direta entre altitude e aumento da precipitação. O ponto 3, local mais elevado da área de estudo $(1131 \mathrm{~m})$, registrou o menor valor médio de chuva acumulada durante os dois trabalhos de campo. Porém, se relacionarmos a hipsometria com a morfologia do terreno, fica nítida a concentração da precipitação nos locais onde a variação topográfica é mais significativa, caso dos pontos 4 e 6 . 
ASSIS, W.L. Variações temporais e espaciais da precipitação em áreas ...

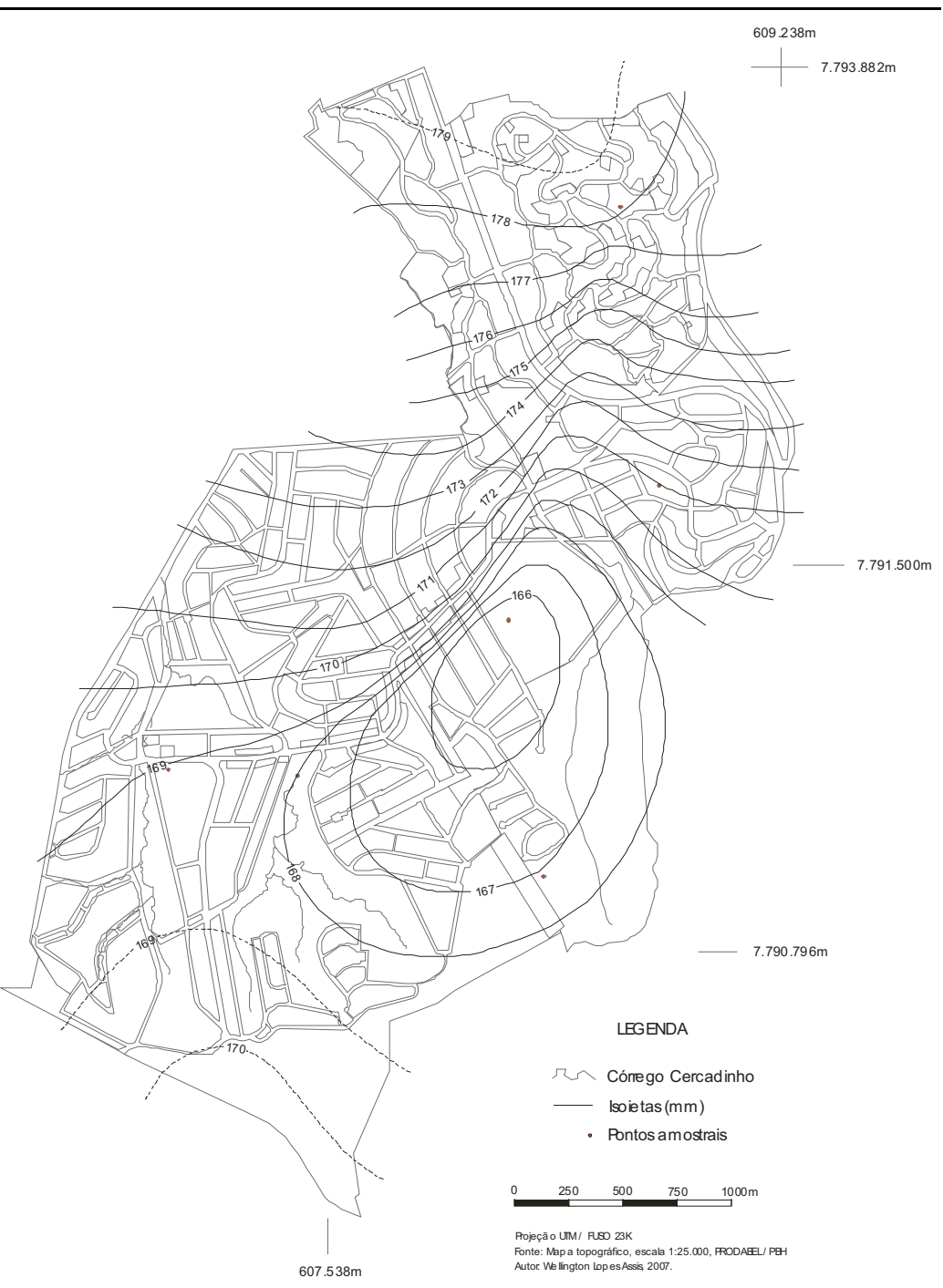

Figura 16: Mapa com a distribuição da precipitação acumulada no período compreendido entre os dias 07/11/07 a $14 / 12 / 07$. 
ASSIS, W.L. Variações temporais e espaciais da precipitação em áreas ...

\section{Considerações finais}

É importante ressaltar que os resultados aqui expostos não esgotam a discussão sobre o comportamento pluviométrico e o clima urbano no município de Belo Horizonte, pois este artigo enfoca somente dois estudos de caso. No entanto, eles permitem extrair algumas considerações sobre a distribuição espacial da precipitação no tecido urbano da cidade.

Os resultados confirmaram as suposições dos modelos teóricos e empíricos de que os condicionantes topográficos e a hipsometria são fatores intensificadores nas precipitações e no aumento das instabilidades atmosféricas (BARRY e CHORLEY, 2003; CRITCHFIELD, 1983; NIMER, 1989).

A comparação entre os dados obtidos em campo e os dados registrados na Estação Meteorológica Oficial do $5^{\circ}$ Distrito de Meteorologia apresentou diferenças significativas nos totais pluviométricos diários, apesar da relativa proximidade entre as duas regiões; porém, os totais acumulados nos bairros Buritis e Estoril foram sempre superiores.

Os pontos de coleta próximos a áreas impermeabilizadas e verticalizadas também registraram totais pluviométricos acima dos observados no $5^{\circ}$ Distrito de Meteorologia. Levantou-se a hipótese de que nestes locais o maior calor acumulado pelas edificações e a presença de materiais particulados contribuem para um aumento significativo da instabilidade atmosférica local.

Com base nos resultados apresentados nesta pesquisa, reforçamos a idéia de que o entendimento dos processos climáticos que afetam a vida nos grandes aglomerados urbanos deve merecer destaque, tanto com referência à situação presente, quanto no que diz respeito à predição e ao planejamento, visando atenuar futuras adversidades.

\section{Referências bibliográficas}

AZEVEDO, T. R. Distribuição espacial da ocorrência dos maiores totais diários de precipitação na RMSP e arredores em função da intensidade relativa da atividade urbana. GEOUSP - Espaço e Tempo, São Paulo, n.12, p. 89-104, 2002. 
ASSIS, W.L. Variações temporais e espaciais da precipitação em áreas ...

BARRY, R. G.; CHORLEY, R. J. Atmosphere, weather and climate. 8. ed. London: Routledge, 2003. 421 p.

CLIMANÁLISE. Cachoeira Paulista: INPE/CPTEC, Março/2006, v.21, n.03. Disponível em: <http://www6.cptec.inpe.br/revclima/>. Acesso em: 10 jul. 2006.

CLIMANÁLISE. Cachoeira Paulista: INPE/CPTEC, Dezembro/2007, v.22, n.12. Disponível em: <http:// www6.cptec.inpe.br/revclima/>. Acesso em: 20 jan. 2008.

CRITCHFIELD, H. J. General climatology. 4. ed. New Jersy: Prentice-Hall, 1983. 453p.

LANDSBERG, H. E. The urban heat island. In: The urban climate. v.28. New York: Academic Press, 1981. 275p.

LOWRY, W. P. Urban effects on precipitation amount. Progress in Physical Geography. v. 22, n. 4, p. 447-520, 1998.

MONTEIRO, C. A. F. Análise rítmica em climatologia: problemas da atualidade climática em São Paulo e achegas para um programa de trabalho. São Paulo, Série Climatologia Dinâmica I, USP-IG, 1971, 21 p.

NIMER, Edmon. Climatologia do Brasil. Rio de Janeiro: IBGE, 1979. 421p.

THIELEN, J.; GADIAN, A. Influence of topography and urban heat island effects on the outbreak of convective storms under unstable meteorological conditions: a numerical study. Meteorological Applications. v. 4, p. 139-149, 1997.

VAREJÃO-SILVA, M. A. Meteorologia e climatologia. Brasília: INMET, Gráfica e Editora Stilo, 2000. 532 p.

VIANELlO, R. L.; ALVES, A. R. Meteorologia básica e aplicações. Viçosa: Imprensa Universitária, 1991. 449 p.

Recebido em maio de 2008 Aceito em junho de 2009 